\title{
CENTRAL SERVICE PROJECT AT ODEABANK: A CASE STUDY EXAMPLE
}

\section{DOI: 10.17261/Pressacademia.2018.914}

PAP- V.7-2018(67)-p.352-355

Hakan Karayel ${ }^{1}$, Aykut Hamit Turan ${ }^{2}$

${ }^{1}$ ODEABANK, Sistem ve Veri Yönetimi, Istanbul, Turkey.

hakankarayel@gmail.com, ORCID: 0000-0001-6160-7541

${ }^{2}$ Sakarya University, İşletme Fakültesi, Sakarya, Turkey.

ahturan@sakarya.edu.tr, ORCID: 0000-0002-8855-4643

\section{To cite this document}

Karayel, H., Turan, A. H. (2018). Central service project at Odeabank: a case study example. PressAcademia Procedia (PAP), V.7, p.352-355.

Permemant link to this document: http://doi.org/10.17261/Pressacademia.2018.914

Copyright: Published by PressAcademia and limited licenced re-use rights only.

\section{ABSTRACT}

Purpose- The subject of this research is the study of the compatibility of information technology projects in Odeabank, which is operating in finance sector, in terms of business and information technology. It is called Central Service Project.

Methodology- In order to monitor the work and secure the contribution of the relevant departments, a working group has been established to cover the four departments of the bank.

Findings- With the new Fax Portal application, we observed that 157 seconds have been saved per transaction and that this benefit has reached the free time of 4.8 personnel in 15.000 transactions per month.

Conclusion- The main objectives of the Central Service Project are to remove manual operations from the Bank Operations Department, to make processes faster, to reduce mistakes in manual operations, and to increase customer satisfaction by performing quick transactions.

Keywords: Information and communication technologies, strategic alignment, finance sector.

JEL Codes: $031,032,033$

\section{ODEABANK'TA MERKEZI HIZMET PROJESI: BİR ÖRNEK OLAY ÇALIŞMASI}

\section{ÖZET}

Amaç- Bu araştırmanın konusu finans sektöründe faaliyet göstermekte olan Odeabank (Banka) bünyesinde yapılan bir bilgi teknolojileri projesinin işletme açısından ve bilgi teknolojileri açısından uyumunu incelemektedir

Yöntem- Bu çalışmanın ilgili her birim tarafından takip edilip katkı yapılabilmesi için banka içerisindeki sorumlu bölümlerin çalışanlarından, dört bölümü kapsayacak şekilde bir çalışma grubu kurulmuştur.

Bulgular- Yeni Faks Portal uygulaması ile işlem başına 157 saniye kazanç sağlandığı ve aylık 15.000 adet işlemde bu faydanın 4.8 adet personelin zamanına denk geldiği görülmüştür.

Sonuç- Merkezi Hizmet Projesinin ana amaçları Banka Operasyon Bölümünün manuel işlemlerden arındırmak, süreçleri daha hızlı hale getirmek, manuel işlemlerde karşılaşılan hataları azaltmak ve hızlı işlem yaparak müşteri memnuniyetini arttırmaktır.

Anahtar Kelimeler: Bilgi ve iletişim teknolojileri, stratejik uyum, finans sektörü.

JEL Kodları: O31, O32, 033

\section{GiRiş}

Genel olarak bilgi kavramı sürekli olmasına rağmen teknolojinin gelişimi sayesinde hızlı şekilde yayılmıştır. Oluşan bu hızlı bilgi yayılımı ve teknolojik yenilikler kurumların gelişimini pozitif yönde desteklemiştir.

Teknolojinin hızlı şekilde gelişmesi ile bu yeni teknolojiler günlük hayatımızın bir parçası haline gelmeye başlamıştır. Tabi ki bu durum çok gecikmeden işletmeler için de önem kazanmış ve işletmeler teknolojileri kullanarak maliyet avantajı, yeni pazar payı oluşturma, verimliliği arttırma vb. nedenlerden bu gelişmeleri kendi süreçlerine eklemişlerdir.

Bu çalışmanın amacı öncelikle Bilgi Teknolojileri ve Stratejik Uyum konuları incelemektir. Sonrasında ise bu kavramların işletmeler açısından ne kadar önemli olduğunu göstermek ve vereceğimiz bir örnek ile somut olarak bunu ifade etmektedir. 
Seçilen örnek Türkiye'de Finans sektöründe faaliyet gösteren bir finans kurumunun bir teknoloji entegrasyon projesidir. Bu proje sonunda nasıl bir teknolojik uyum oluştuğu incelenmiştir.

Bu çalışma içerisinde aşağıdaki konular incelenmektedir;

- $\quad$ Bilgi, Bilgi Teknolojileri, Bilgi Teknolojilerinin Gelişimi

- $\quad$ Stratejik Uyum, Stratejik Uyum Modelleri

- $\quad$ Finans Sektöründe Bilgi Teknolojilerinin Uyumu

- Merkezi Hizmet Projesi

- $\quad$ Proje Değerlendirmesi

\section{ILGILI KAVRAMLAR}

\subsection{Bilgi Teknolojileri (BT)}

Bilgi teknolojileri kavramının tanımı şu şekildedir;

- $\quad$ "Verilerin kayıt edilmesi, saklanması, belirli bir işlem sürecinden geçirmek suretiyle bilgiler üretilmesi, üretilen bu bilgilere erişilmesi, saklanması ve nakledilmesi gibi işlemlerin etkili ve verimli yapılmasına olanak tanıyan teknolojiler" (BEHAN ve HOLMES 1990, s.39.)

- $\quad 21$ nci yüzyılın başına kadar olan gelişmeler insanoğlunu modern bir yaşantıya kavuşturmuştur. Ancak 21nci yüzyıl sonrasında yaşanan geçişmeler diğer tüm zamanlardakinden daha hızlı gerçekleşmiş ve insanları bilgi teknolojileri çağışa sokmuştur.

- Son yüz yılda yaşanan hızlı gelişim ile artık Bilgi Teknolojileri kavramı hayatın her alanında bulunmaktadır. Bu gelişmeler insanların ve işletmelerin günlük hayatlarını ve faaliyetlerinin tamamen değiştirmiştir.

İşletmelerdeki BT Gelişimi

İnsanlık tarihi süresinde yaşanan süreçler farklı isimler verilerek incelenmesi kolaylaştırılmış ve diğer insanlarında anlaması sağlanmıştır. Bu süreçler bir öncekinin üzerine farklı değerler ekleyerek gelişimini sürdürmüştür. İnsanlığın tarihsel süreci tarım toplumundan başlayıp sanayi toplumuna oradan da bilgi toplumuna gelişmiştir.

İçinde bulunduğumuz bilgi toplumu içerisinde kullanılan bilgi ve veri kavramlarının ama kullanım aracı bilgi teknolojileri olmuştur. Bu şekilde insanlık bilgi teknolojilerini de kullanarak hızlı şekilde ilerlemeye devam etmektedir.

Bilgi Teknolojilerinin gelişim süreci incelendiğinde İlkel ve tarım toplumu, Sanayi devrimi süreci ve bilgi çağı toplumu süreçlerinin oluştuğu görülmektedir.

Tarım ve sanayi çağında da önemli olan bilgi, bilgi çağı ile birlikte gelişen bilgi teknolojilerinin ayrılmaz bir parçası haline gelmiştir. Bilginin artması, kolay ulaşılabilir olması ve hızlı işlenmesi sonucunda bilgi çağına geçilmiş ve bilgi teknolojilerinin gelişimi de çok hızlanmıştır.

Tabiki bilgi teknolojileri gelişimi açısından incelendiğinde son yüz yıldır içerisinde olduğumuz bilgi çağı en önemli süreci kapsamaktadır.

Bu süreçte yapılan en önemli buluş ve yenilik bilgi toplumunun ayrılmaz bir parçası ve itici günü bilgisayardır. Bilgi toplum için çok önemli bir yer almaktadır ve bu bilgiye erişim, bilginin depolanması ve geliştirilmesi işlemlerinin en temel aracı bilgisayardır. Bilgisayarında tarihsel gelişimine bakıldığında en önemli konu ikili sayı sisteminin gelişmesi ve bilgisayar alanında kullanıma başlanmasıdır (WILLIAMS 1982, s.1192).

\subsection{Stratejik Uyum}

Kurum ve işletmelerde stratejik uyum bilgi teknolojileri ve kabul edilen finansal performans ölçümlerinin arasındaki pozitif bir ilişki gösterme kapasitesidir (STRASSMANN 1998).

Burada dikkat edilmesi gereken nokta bilgi teknolojileri yöneticilerinin başarı kriterlerini belirlerken tüm kurum ve işletmelerde kabul gören bir ölçüt olması açısından bu ölçütün finansal olmasıdır.

Bilgi teknolojileri ve iş stratejilerine ilişkin başka tanımlarda bulunmaktadır. Henderson ve Venkatman tarafından yapılan tanımda bunlardan bir tanesidir. Bu açıklama iki varsayıma dayanmaktadır.

İlk varsayım kurum ya da işletmenin pazardaki rekabetçi konumunu, ekonomik performansını ve yönetim yapısını destekleyen stratejik uyum ile doğrudan ilgilidir.

İkinci varsayım ise bu stratejik uyumun dinamik bir yapıda olduğunu, alınan kararların birbirine benzeyen olaylar meydana getireceğini ve bu olaylar sonrasında da tepkilerin oluşacağını belirtir (Henderson \& Venkatraman, 1993).

Kavramsal olarak açıkladığımız stratejik uyum, iş stratejileri,bilişim teknolojileri stratejileri, örgütsel mimari ve süreçler ve bilişim sistemleri altyapısı ve süreçleri arasındaki uyumu temsil etmektedir.

Bu konudaki etkileşim aşağıdaki şekilde gösterilmektedir.

Finans Sektöründe BT Uyumu

Bu araştırmanın konusu finans sektöründe faaliyet göstermekte olan Odeabank (Banka) bünyesinde yapılan bir bilgi teknolojileri projesinin işletme açısından ve bilgi teknolojileri açısından uyumunu incelemektedir. 
Yapılan bu çalışmaya "Merkezi Hizmet Projesi" adı verilmiştir.

Çalışma özet olarak Banka'ya iletilen faks emirlerinin mevcut sürecini incelemek ve bu süreçlerin otomasyonu için bulunan mevcut bilgi teknolojileri çözümlerini değerlendirerek çalışmaları daha verimli hale getirmektir.

Bu çalışmanın ilgili her birim tarafından takip edilip katkı yapılabilmesi için banka içerisindeki sorumlu bölümlerin çalışanlarından, dört bölümü kapsayacak şekilde bir çalışma grubu kurulmuştur. Bu dört bölüm ve işlevleri aşağıda belirtilmiştir:

Operasyon Bölümü: İlgili iş koludur. Müşterilerden faks sistemi ile gelen emirlerin yerine getirilmesinden sorumlu bölümdür.

İş Çözümleri Bölümü: Projeyi genel olarak ele alan ve genel banka yararını düşünerek en uygun çözümün uygulanması için alternatifleri değerlendiren bölümdür.

Sistem Yönetimi: Bilgi Teknolojileri altında uygulamaları yöneten bölümdür. Proje sonucunda yeni bir yazılım ya da çözümün alınması, değerlendirilmesi ve yönetiminden sorumludur.

Organizasyon Bölümü: Yapılacak bu çalışmalar ile yeni devreye alınacak yazılım ve sistemler sonucunda Banka'nın mevcut organizasyonunun değerlendirip değişim yapılması gerekmediği, yani teknolojik gelişim ile organizasyonel yapının uyumundan sorumlu ekiptir.

Mevcut yapıda, Banka genelinde faks gönderimi ve alımı için RightFax yazılımı kullanılmaktadır. Bu yazılım ile gelen fakslar faks makinelerinden kağıda basılı olarak değil de RightFax yazılımının FaxUtil uygulamaları üzerinden dijital olarak görülebilmektedir.

RightFax sunucu uygulaması ve kullanıcı bilgisayarlarında kullanılan FaxUtil yazılımı ile gelen fakslar mail gibi bilgisayar ekranından görülebilmektedir. Bu akışın çizildiği genel bir faks topolojisi şeklini aşağıda görebilirsiniz.

Merkezi Hizmet Projesi ile hedeflenen FaxUtil uygulaması ile manuel takip edilmesi gereken müşterilerin faks eminlerinin yeni bir web uygulaması (Portal) ile kolay takip edilebilir ve merkezileştirilmiş hale getirilmesidir.

Projenin diğer bir amacı ise yeni uygulama ile hafifleyecek iş yükü ile birlikte şube operasyon personelinin diğer süreçlere ve özellikle pazarlama, satış süreçlerine daha fazla zaman ayırmasını sağlamaktır.

Yapılan araştırma sonrasında FaxUtil uygulamasının özelliklerinin artırılması konusunda yine aynı firma tarafından sağlanan Faks Portal ürünü değerlendirilmiştir. Ürünün incelenmesi sonrasında yeni Faks Portal uygulamasının faks takibi için uygun ve verimli bir ekran sunduğu görülmüştür

Bu ekran incelendiğinde şubeler özelinde yapılan iş takiplerinin tek bir ekrandan ve tek bir ekip ile yapılmasının daha uygun olacağı ve bu sayede şubelerdeki personelin zamanının boşa çıkacağı görülmüştür.

Yapılan yeni projenin fayda maliyet analizi yapılmış ve 5 yıl için bankaya nasıl bir fayda sağlayacağı değerlendirilmiştir.

Yeni Faks Portal uygulaması ile işlem başına 157 saniye kazanç sağlandığı ve aylık 15.000 adet işlemde bu faydanın 4.8 adet personelin zamanına denk geldiği görülmüştür.

Projedeki birim malitlere kazanca ek olarak ilk yatırım maliyeti ve ürünün devreye alınması sonrasında 5 yıllık kazançta hesaplanmıştır.

Yapılan bu fayda analizleri sonrasında Banka sağlanan 4.8 kişilik tasarrufun nasıl değerlendirilebileceğini araştırmıştır.

Her şubede devam eden operasyonlar gereği operasyon bölümünden personel çıkarılamamaktadır. Bu neden ise Operasyon ve Organizasyon bölümleri konuyu değerlendirerek bu süreci Merkezi Operasyon bölümüne taşımıştır. Bu şekilde daha az kaynak ile aynı işlem yapılabilecektir.

Ayrıca şube operasyon personeli üzerinden kaldırılan müşteri faks talimatları operasyonlarının yerine Banka bu personele pazarlama ve satış hedefleri vermiştir.

Böylece banka aylık 4.8 adam günlük tasarrufunu daha fazla pazarlama ve satış faaliyeti yaparak karlılığını arttırmıştır.

\section{SONUÇ VE DEĞERLENDIRME}

Ayrıntılarını incelediğimiz Merkezi Hizmet Projesinin ana amaçları Banka Operasyon Bölümünün manuel işlemlerden arındırmak, süreçleri daha hızı hale getirmek, manuel işlemlerde karşılaşılan hataları azaltmak ve hızlı işlem yaparak müşteri memnuniyetini arttırmaktır.

Yapılan ilk çalışmalar ve bilgi teknolojileri çözümleri araştırılması sonrasında yukarıdaki faydalara ek olarak Faks Portal yazılımı ile personel sayısından tasarruf yapılacağı görülmüştür

Ayrıca yeni bilgi teknolojileri çözümü ile yapılan değerlendirmeler sonrasında Banka organizasyon ve işleyiş şeklini değiştirerek yapılan operasyonları şube operasyon bölümlerinden alarak Merkezi Operasyon bölümüne vermiştir.

Bu karar organizasyonel açıdan bilgi teknolojileri ile kurumların stratejik uyumuna güzel bir örnek oluşturmaktadır.

Yapılan çalışma sonucunda aşağıdaki faydalar sağlamıştır. Bu faydaları Banka içi faydalar ve müşteri tarafındaki faydalar olarak ikiye ayırabiliriz. 
Banka için faydaları

- $\quad$ Daha az personel ile işlemler yapılabilmekte ve maliyet avantajı sağlanmaktadır.

- Bilgi teknolojilerindeki gelişmeler yakından takip edilmekte ve hızı entegrasyon ise süreçler verimli hale getirilmektedir.

- Yapılan kompleks işlemlerin takibi kolaylaştırılmıştır.

- Faks Portal yazılımı ile daha önceden alınamayan performans ve işlem raporları alınabilmektedir.

- Personel sayısından yapılan kazanım ile pazarlama ve satış faaliyetlerine daha çok zaman ayılmakta ve kazanımlar artmaktadır.

- Yapılan çalışma sonucunda aşağıdaki faydalar sağlamıştır. Bu faydaları Banka içi faydalar ve müşteri tarafındaki faydalar olarak ikiye ayırabiliriz.

Müşteri tarafındaki faydaları

- $\quad$ Süreçler hızlanmış ve iletilen talepler daha kısa sürede karşılanmaktadır.

- Işlemlerin hızlı tamamlanması sonucunda müşteri memnuniyeti artmaktadır.

- $\quad$ Şubede ilk ve en önemli işi müşteri ile ilgilenmek olan personel diğer operasyonel işlerini Merkezi Operasyon bölümüne devrederek müşterilere daha fazla zaman ayırabilmektedir.

- $\quad$ Şube operasyon personeline verilen yeni pazarlama ve satış hedefleri ile müşteriler Banka faaliyet ve kampanyalarından daha iyi ve hızı bilgi almaktadırlar.

- Yapılan ișlemlerde iș takibi iyi yapılmakta ve hata oranları azalmaktadır. Bu sayede müșterilerden gelen talepler ve ișlem hacmi artmaktadır.

Yaptığımız bu çalışma ile yeni gelişen bilgi teknolojileri çözümleri ile işletmelerin stratejik uyumlarını değerlendirdik ve somut bir örnek ile bu uyum sürecini açıkladık. Bu çalışmadaki kaynaklar ile farklı sektörlerdeki yöneticiler kendi firmalarındaki süreçleri bu kapsamda değerlendirerek süreçlerini iyileştirebilirler.

Akademik açıdan değerlendirirsek, bu çalışmayı inceleyen öğrenciler ve akademisyenler bu çalışmayı bir şablon olarak kullanabilirler. Biz bu çalışmada bir süreci ele aldık ve bilgi teknolojileri çözümü ile verimin arttırdık. Sonrasında yapılan değerlendirmeler ile işletmenin stratejik uyum planııı da bu çalışmalardan etkilendiğini belirttik. Bu çalışma taslak olarak alınarak farklı sektörler ya da farklı süreç yada uygulamalar incelenebilir.

Bu çalışmanın diğer benzer çalışmalardan farklı yani finans sektöründen bir örnek üzerinden ilerlenmesi, çalışmaların finansal etkilerinin net olarak hesaplanıp belirtilmesi ve stratejik uyum konusunda örgütsel yani personel yapılanması içeren bir sonucu incelemesidir.

\section{KAYNAKLAR}

Behan, K., Holmes. D. (1990). Understanding information technology. Printice Hall, 2nd ed. NY, 1990, s.1'den aktaran BENSGHIR, A.g.e., s.39. s.1.

Williams, A. (1982). The history of technology-the twentieth century C. 1900-1950, Part II, 1982, s.1192.

Strassmann, P. (1998). What is alignment? Alignment is the delivery of the required results. Accessed on 0821,2012 at http://www.strassmann.com/pubs/alignment/

Henderson, J. C., Venkatraman, N. (1993). Strategic alignment: leveraging information technology for transforming organizations. IBM System Journal Vol 32, 472-484.

Henderson, J., Venkatraman, N. (1989). Strategic alignment: a framework for strategic information technology management. ss.22-23-24, s.27. 